\title{
Preparedness of Healthcare Workers towards Handling COVID-19 Outbreak in the Gambia
}

\author{
Joseph W. Jatta ${ }^{1,2}$, Jean Claude Romaric Pingdwindé Ouédraogo ${ }^{1,3}$, Yusupha Sanyang ${ }^{4}$, \\ Daniel Nebongo ${ }^{1,5}$, Tahir Ahmed Touray ${ }^{4}$, Dodou Sanyang ${ }^{4,6}$, Thomas Senghore ${ }^{4 *}$ \\ ${ }^{I}$ WHO/TDR Scholar, Department of Epidemiology and Disease Control, School of Public Health, University of Ghana, Accra, Ghana. \\ ${ }^{2}$ Slum and Rural Health Initiative Network, Research and Collaboration Department, SRHIN/Africa, Nigeria. \\ ${ }^{3}$ Département Médecine et Pharmacopée Traditionnelles/Pharmacie, Institut de Recherche en Sciences de la Santé (IRSS), Ouagadougou, Burkina Faso. \\ ${ }^{4}$ Department of Nursing and Reproductive Health, School of Medicine \& Allied Health Sciences University of The Gambia, Banjul Campus, The Gambia. \\ ${ }^{5}$ Health and Human Development (2HD) Research Network, Douala, Cameroon. \\ ${ }^{6}$ School of Community Health Nursing, Mansakonko, The Gambia.
}

\begin{abstract}
Background: The novel Coronavirus (COVID-19) outbreak that began in Wuhan, China rapidly became a public health concern and a challenge for healthcare systems globally. In the wake of the first confirmed case in The Gambia, concerns were raised in some quarters about the health system's preparedness to handle the outbreak. Therefore, we aimed to assess health personnel's knowledge and preparedness in fighting the COVID-19 outbreak in The Gambia. Methods: A crosssectional survey was conducted using self-administered questionnaires distributed online through social media. Descriptive, bivariate, and binary logistic analyses were done using SPSS Version 22. Results: We obtained 333 valid responses. Most participants reported that their health facility has some form of preparedness; however, only a small proportion reported enough PPEs in the health facility. About half (50.5\%) showed good knowledge of COVID-19. There was a statistically significant difference among the professions regarding their reaction if they were found positive of COVID-19 $(p=0.006)$. There was a significant association between health professions [other professions (Odds ratio $[\mathrm{OR}]=0.2$, 95\% Confidence interval $[\mathrm{CI}]: 0.04-0.9 ; p=0.038)]$ and overall knowledge of COVID-19. Conclusion: Our findings showed some form of preparedness towards COVID-19 among healthcare workers. However, many aspects, such as the availability of PPEs and their proper use and knowledge, need improvement. Thus, training and an adequate supply of equipment are required to better respond to upcoming COVID-19 waves and future outbreaks.
\end{abstract}

Keywords: COVID-19; Preparedness; Knowledge; Healthcare Workers; The Gambia.

\section{Introduction}

Over the past two decades, the world has witnessed unprecedented waves of communicable disease outbreaks that the World Health Organization has declared to be at least public health emergencies of international concern [1]. Most developing countries are deemed at high risk for these outbreaks due to the weak health systems [2]. For instance, in 2014, during the West African Ebola outbreak, the health institutions of affected countries were overwhelmed and

* Corresponding author: tsenghore@utg.edu.gm

\section{doi) http://dx.doi.org/10.28991/SciMedJ-2021-03-SI-5}

$>$ This is an open access article under the CC-BY license (https://creativecommons.org/licenses/by/4.0/).

(C) Authors retain all copyrights. 
were unable to effectively handle the outbreak [3]. Several factors have been identified for the inability to effectively contain the outbreak, including lack of necessary resources, inadequate knowledge of the disease dynamic, and unskilled frontline health workers [4].

In late December 2019, a new outbreak of COVID-19 started in Wuhan, China quickly spread throughout the world [5] and eventually became a serious global public health threat. In the wake of this, the Gambia government through the Ministry of Health $(\mathrm{MoH})$ stepped up an effort to prepare and respond in the event of any cases of COVID-19. In March 2020, the first case was confirmed, thus sparking a series of government measures to contain the spread. However, the effectiveness of these measures is unclear and specifically, the preparedness of healthcare workers in handling cases. Given this uncertainty, we aim to investigate the state of preparedness of healthcare workers in the Gambia towards controlling the COVID-19 outbreak, thereby identifying gaps. The findings may help guide policy formulations and strategies to handle future outbreaks in the Gambia.

\section{Research Methodology}

\subsection{Study Design and Population}

A cross-sectional study design was used, and data collection lasted for more than a month (between April 23 to May 31). The target population was all health professionals actively working in The Gambian healthcare system at the survey time.

\subsection{Sampling and Data Collection}

Given the data collection method, a convenience sampling procedure was used to enrol respondents for the study. Data was collected through an online survey technique. The questionnaires were designed using Survey Monkey on the google platform. The web links were distributed through e-mails, webpages, and social media platforms (WhatsApp and Facebook).

The questionnaire was adapted from a previous questionnaire that was already validated for use [6]. The instrument was pre-tested to ensure consistency. The questionnaire was validated through face validity.

\subsection{Measures}

Health-workers preparedness towards the COVID-19 outbreak was checked through 11 questions, with answers recorded in either 'Yes', 'No' or 'Not sure'. Their attitude was assessed by the willingness to attend to a patient with acute respiratory illness and the reaction if tested positive to COVID-19 on a Likert scale with 3 and 4 levels, respectively.

The overall awareness of workers on COVID-19 was evaluated and the knowledge considered in 4 aspects: symptoms, preventive measures, actions to be taken when experiencing acute respiratory illness, maintain social distancing.

\subsection{Data Analysis}

The submitted responses were downloaded from the Google platform, exported to Microsoft excel and later imported to SPSS version 22 for analysis. Descriptive and analytical statistics were used. Bivariate analysis and multivariate logistic regression were conducted to test associations.

\subsection{Ethics Approval and Consent to Participate}

Participants gave their informed consent to participate in the survey before filling the online questionnaire. The study was considered below minimal risk.

\section{Results}

A total of 371 participants took part in the survey; however, only 333 were eligible and were included in the analysis. Table 1 shows the demographic characteristics of the participants. The majority were males $(60.4 \%)$, had between 20 and 29 years $(48.6 \%)$ and were holders of certificate/diplomas $(50 \%)$. Over three quarters $(76 \%)$ of the participants were nurses/ midwives with over half (54.7\%) working in hospitals.

Table 2 shows the results of the health workers preparedness toward COVID-19. A little over half of the health workers $(50.5 \%)$ reported their facilities had an emergency plan for COVID-19, as at the study period. More than half of the participants reported that their health facilities had guidelines for collaborating with other professionals within the facility (53.8\%). Sixty-two said their facility had a specific emergency contact list for persons who needed swift response in the event of COVID-19. A vast number (91.6\%) of the health workers reported they had always 
communicated with other staff on COVID-19, and 83\% reported they had spoken with their patients about COVID-19. About two-thirds $(63.1 \%)$ reported their facility screens patients and visitors for acute respiratory symptoms, and only a small proportion (8.4\%) reported that their facilities had enough PPEs. About forty-three per cent (42.9\%) reported their facilities to ensure proper use of PPE and little less than one-third (26.1\%) said their facilities conduct an inventory of available PPEs. About one-third (35.7\%) reported their health facility had a plan to encourage sick staffs to stay at homes if they experience acute respiratory symptoms.

Table 1. Socio-demographic information of Health workers $(n=333)$

\begin{tabular}{|c|c|c|}
\hline Variables & Frequency & Percentage \\
\hline \multicolumn{3}{|l|}{ Age (years) } \\
\hline $20-29$ & 165 & 49.6 \\
\hline $30-39$ & 148 & 44.4 \\
\hline $40+$ & 20 & 6.0 \\
\hline \multicolumn{3}{|l|}{ Gender* } \\
\hline Female & 128 & 38.4 \\
\hline Male & 201 & 60.4 \\
\hline \multicolumn{3}{|l|}{ Education Level * } \\
\hline Certificate/ Diploma & 177 & 53.2 \\
\hline Undergraduate & 114 & 34.2 \\
\hline Graduate/Postgraduate & 38 & 11.4 \\
\hline \multicolumn{3}{|l|}{ Profession } \\
\hline Nurse/Midwife & 253 & 76.0 \\
\hline PHO/Lab Officer & 40 & 12.0 \\
\hline Medical doctor & 28 & 8.4 \\
\hline Others & 12 & 3.6 \\
\hline \multicolumn{3}{|l|}{ Work Place } \\
\hline Hospital & 182 & 54.7 \\
\hline Health centre & 129 & 38.7 \\
\hline PHC facility & 16 & 4.8 \\
\hline Others & 6 & 1.8 \\
\hline \multicolumn{3}{|l|}{ Location of Work } \\
\hline Banjul & 87 & 26.1 \\
\hline Knifing Municipal Council & 77 & 23.1 \\
\hline West Coast Region & 55 & 16.5 \\
\hline North Bank Region & 29 & 8.7 \\
\hline Lower River Region & 18 & 5.4 \\
\hline Central River Region & 24 & 7.2 \\
\hline Upper River Region & 43 & 12.9 \\
\hline
\end{tabular}

*Frequencies do not add up to total due to missing responses

Table 2. Health workers preparedness towards the COVID-19 outbreak

\begin{tabular}{|c|c|c|c|}
\hline Questions & $\begin{array}{c}\text { Yes } \\
\text { n }(\%)\end{array}$ & $\begin{array}{l}\text { No } \\
\text { n }(\%)\end{array}$ & $\begin{array}{l}\text { Not Sure } \\
\text { n }(\%)\end{array}$ \\
\hline 1. Does your facility have an emergency plan for COVID-19? & $168(50.5)$ & $98(29.4)$ & $67(20.1)$ \\
\hline 2. Are there clear guidelines for collaborating with other professionals in your facility? & $179(53.8)$ & $105(31.5)$ & $49(14.7)$ \\
\hline 3. Does your facility have an emergency contact list specifically? & 209 (62.8) & $54(16.2)$ & $70(21.0)$ \\
\hline 4. Do you communicate with other staffs on COVID-19? & $305(91.6)$ & $22(6.6)$ & $6(1.8)$ \\
\hline 5. Do you communicate with your patients on COVID-19? & $276(82.9)$ & $45(13.5)$ & $12(3.6)$ \\
\hline 6. Does your facility screen patients \& visitors for symptoms of acute respiratory illness? & $210(63.1)$ & $96(28.8)$ & $27(8.1)$ \\
\hline 7. Does your facility have enough PPE? & $28(8.4)$ & 271 (81.4) & $34(10.2)$ \\
\hline 8. Does your facility ensure the proper use of PPE? & $143(42.9)$ & $120(36.0)$ & $70(21.0)$ \\
\hline 9. Is there a system in place to conduct an inventory of available PPE? & $87(26.1)$ & $107(32.1)$ & $139(41.7)$ \\
\hline 10. Is there a system in place to encourage sick staff to stay at home? & $119(35.7)$ & $116(34.8)$ & $98(29.4)$ \\
\hline $\begin{array}{l}\text { 11. Are there protocols to separate patients with respiratory symptoms, so they are not } \\
\text { waiting among other patients seeking care? }\end{array}$ & $142(42.6)$ & $113(33.9)$ & $78(23.4)$ \\
\hline
\end{tabular}


Most of the health workers reported willingness to attend to patients with acute respiratory illness (very willing [61\%] and somewhat willing [30.9\%], while 55\% express becoming sad if they tested positive for COVID-19 (Table $3)$. There was a statistically significant difference among the professions regarding their reaction if they were found to test positive of COVID-19 $(p=0.006)$. The difference was not significant when considering their willingness to attend to patients with an acute respiratory disease $(p=0.067)$.

Table 3. Health workers' attitude towards COVID-19

\begin{tabular}{|c|c|c|c|c|c|c|}
\hline Variable & $\begin{array}{l}\text { Total } \\
\text { n }(\%) \\
\end{array}$ & $\begin{array}{c}\text { Nurse/midwife } \\
\text { n }(\%)\end{array}$ & $\begin{array}{c}\text { Doctor } \\
\text { n }(\%) \\
\end{array}$ & $\begin{array}{c}\text { PHO/Lab } \\
\text { Officer n (\%) } \\
\end{array}$ & $\begin{array}{c}\text { Others } \\
\text { n }(\%)\end{array}$ & $p$-value \\
\hline Willingness to attend to a patient with acute respiratory illness & & & & & & 0.067 \\
\hline Very willing & $203(61.0)$ & $147(58.1)$ & $21(75.0)$ & $19(61.3)$ & $16(76.2)$ & \\
\hline Somewhat willing & $103(30.9)$ & $81(32.0)$ & $6(21.4)$ & $12(38.7)$ & $4(19.0)$ & \\
\hline Not willing & $27(8.1)$ & $25(9.9)$ & $1(3.6)$ & $0(0.0)$ & $1(4.8)$ & \\
\hline Reaction if tested positive to COVID-19 & & & & & & 0.006 \\
\hline Sad & $186(55.9)$ & $148(58.5)$ & $13(46.4)$ & $14(45.2)$ & $11(52.4)$ & \\
\hline Normal & $95(28.5)$ & $67(26.5)$ & $6(21.4)$ & $13(41.9)$ & $9(42.9)$ & \\
\hline Disappointed & $38(11.4)$ & $32(12.6)$ & $3(10.7)$ & $3(9.7)$ & $0(0.0)$ & \\
\hline Annoyed/Worried & $14(4.2)$ & $6(2.4)$ & $6(21.4)$ & $1(3.2)$ & $1(4.8)$ & \\
\hline
\end{tabular}

PHO, Public Health Officer

Significance at $p<0.05$

Tables 4 and 5 show health workers awareness and knowledge of COVID-19. Almost all (98.2\%) of the respondents were aware of the existence of COVID-19 in The Gambia, with the majority knowledgeable on the symptoms and preventive measures (Table 4). However, only about half $(50.5 \%)$ were considered to have good knowledge when the overall knowledge score was computed. The mean (SD) and median knowledge scores were $9.6( \pm 2.33)$ and 10 , respectively, with a maximum score of 18. There was a significant association between profession and overall knowledge. Those categorized as other professions (Odds ratio $[\mathrm{OR}]=0.2$, 95\% Confidence interval [CI]:0.04-0.9; $p=0.038$ ) were less likely to have good knowledge of COVID-19, as compared to nurses/midwives.

Table 4. Awareness and knowledge of health workers on COVID-19

\begin{tabular}{|c|c|c|}
\hline \multirow{2}{*}{ Variable } & \multicolumn{2}{|c|}{ Total $(n=333)$} \\
\hline & Frequency & $\%$ \\
\hline Awareness of COVID-19 in The Gambia (yes) & 327 & 98.2 \\
\hline \multicolumn{3}{|l|}{ Knowledge of COVID-19 symptoms (yes) } \\
\hline Fever & 326 & 97.9 \\
\hline Cough & 318 & 95.5 \\
\hline Difficulty in breathing & 326 & 98.2 \\
\hline Tiredness & 115 & 34.5 \\
\hline Body aches & 88 & 26.4 \\
\hline Runny nose & 130 & 39.0 \\
\hline Sore throat & 261 & 78.4 \\
\hline \multicolumn{3}{|l|}{ Preventive measures when attending to patients (yes) } \\
\hline Wear the same glove & 5 & 1.5 \\
\hline Wear the same face mask & 14 & 4.4 \\
\hline Discard and use a new glove & 221 & 66.4 \\
\hline Discard and use a new face mask & 241 & 72.4 \\
\hline Wash hands under running water & 314 & 94.3 \\
\hline Apply alcohol-based hand sanitiser & 215 & 64.6 \\
\hline \multicolumn{3}{|c|}{ Actions to take during the experience of acute respiratory illness (yes) } \\
\hline Self-quarantine & 178 & 53.5 \\
\hline Stay at home with family & 197 & 59.2 \\
\hline Inform management & 155 & 46.5 \\
\hline Go for voluntary testing & 9 & 2.7 \\
\hline \multicolumn{3}{|l|}{ Maintain Social distancing } \\
\hline Sit at last three meters apart & 323 & 69.7 \\
\hline
\end{tabular}


Table 5. Association between profession and knowledge on COVID-19

\begin{tabular}{|c|c|c|c|c|c|c|}
\hline \multirow{2}{*}{ Variables } & \multicolumn{5}{|c|}{ Overall Knowledge level } & \multirow{2}{*}{$p$-value } \\
\hline & Poor, n (\%) & Good, n (\%) & $p$-value & OR & CI & \\
\hline All & $165(49.5)$ & $168(50.5)$ & & & & \\
\hline Profession & & & 0.042 & & & \\
\hline Nurse /Midwife & $128(77.6)$ & $125(74.4)$ & & 1.00 & ref & \\
\hline Medical doctor & $11(6.7)$ & $17(10.1)$ & & 1.44 & $0.68-3.13$ & 0.339 \\
\hline $\mathrm{PHO} /$ Lab Officer & $16(9.7)$ & $24(14.3)$ & & 1.50 & $0.80-2.82$ & 0.209 \\
\hline Other & $10(6.1)$ & $2(1.2)$ & & 0.20 & $0.04-0.91$ & 0.038 \\
\hline
\end{tabular}

OR Odds ratio; CI, Confidence interval; PHO, Public Health Officer

Significance at $\mathrm{p}<0.05$

\section{Discussion}

This study investigated healthcare workers' preparedness and their knowledge towards COVID -19 outbreak in The Gambia. The questionnaire was distributed online, which enables the research to have a wider reach across all the health regions in the country and makes it possible for many health workers to participate. The findings showed that over $50 \%$ of the participants were holders of certificates and diplomas, $76 \%$ of whom were nurses and midwives. This is not surprising as the nurses form a larger percentage of the health workforce in the Gambia.

We found that some form of preparedness was in place, with a good knowledge of participants on COVID-19 and a positive attitude towards COVID-19. Since COVID-19 is new, health officials are expected to read and find more information on the disease, which might be responsible for their high knowledge [7, 8].

As frontliners, healthcare workers' preparedness at the early stage of the outbreak indicates how well the response would be in the health facilities. Preparedness includes health facilities having an emergency plan for COVID-19, keeping an emergency contact list, screening all patients and visitors for symptoms of COVID-19 and communicating to staff and patients on the disease. Our study found that only half of the facilities had an emergency plan and contact list relevant in response to the pandemic. The lack of a preparedness plan negatively impacts patient management, especially that of potential COVID-19 cases. It was also reported that some of the facilities did not have a system in place for screening patients for COVID-19. The absence of such a triage system could lead to a potential outbreak originating within the health facilities. The study participants also reported some weaknesses that include the lack of PPEs regular inventory, the availability of limited PPEs and inappropriate use of existing PPEs. This showed an inadequate state of preparedness in our hospitals and health centres to face the pandemic. The inability of the health facilities to provide adequate protective equipment can expose health workers to infection. There is an increase in the number of COVID-19 infections among health workers since the beginning of the COVID-19 [9]. Additionally, inadequate use of PPEs expose health workers to be at additional risk of COVID-19 infection and increased susceptibility [10]. The shortage of PPEs was making doctors and nurses buy their PPEs to protect themselves from the disease [11].

The participants showed good awareness of COVID-19 in The Gambia, with other health professionals less likely to have good knowledge than nurses/midwives. The study was carried out in April-June 2020, shortly after the first case was declared in the country on March 17, 2020, but long after the pandemic began in China in late 2019. So, it is not surprising that healthcare workers have a good knowledge of the most prevalent clinical features like fever, cough, and difficulty breathing amongst COVID-19 patients [12]. However, it is crucial to know that symptoms and signs depend on the severity of COVID-19 and to recognize infrequent evocative signs [13]. Behind diseases signs, most participants have evoked hand washing, the discard and use of a new glove, and alcohol-based hand sanitiser as primary preventive measures. Implementation and adherence to preventive measures are vital in limiting and controlling the spread of highly transmissible diseases like COVID-19. In this pandemic, there has been a promotion of barriers like mask-wearing, handwashing, hand sanitiser and social distancing. It is moreover the essence of confinement, quarantine, or isolation, to limit risky contacts. Washing hands has been adopted by the health sector since Ignaz Semmelweis demonstrated its importance in preventing transmissible health conditions. It would go with the use of alcohol or alcohol-based solutions in health facilities and the use of gloves and PPEs during this COVID-19 pandemic. However, it is worrying one-third of healthcare workers missed the discard and use of a new glove when the strategy of infections control in health centres is based on the single-use of consumables and proper handwashing. Poor management of biological waste constitutes a risk for nosocomial transmission of communicable diseases like COVID-19, mostly as health workers were willing to attend to COVID-19 patients. There was a positive attitude towards COVID-19, but most respondents said they would feel sad or disappointed/worried if they test positive for COVID-19. 
Our findings are subject to the following limitations. First, due to the cross-sectional nature of our data, we cannot infer causation. Second, the survey was online and may not reach all health workers and may not represent the country's general health workers. Finally, many activities have taken place from data collection to writing this paper, which may have led to changes in the current statues. However, our study is the first in the Gambia to describe health workers' preparedness towards the COVID-19 outbreak in the Gambia. Our findings could help in determining plans to handle future outbreaks and COVID-19 upcoming waves.

\section{Conclusion}

We found some form of preparedness against the COVID-19 pandemic in The Gambia, with most health workers showing good knowledge of COVID-19. However, many aspects, such as the availability of PPEs and their proper use and knowledge, need to be improved. Thus, there is a need for training and an adequate supply of equipment to better respond to this and future outbreaks.

\section{Abbreviations}

$\begin{array}{llll}\text { PPE: } & \text { Personal Protective Equipment } & \text { COVID-19: } & \text { Coronavirus Disease } 2019 \\ \text { SD: } & \text { Standard Deviations } & \text { MoH: } & \text { Ministry of Health } \\ \text { PHC: } & \text { Primary Healthcare } & & \end{array}$

\section{Declarations}

\subsection{Author Contributions}

J.W.J., T.S., J.C.R.P.O. and Y.S. made substantial contributions to the conception, design, literature search, acquisition of the data, analysis, interpretation of data, drafting of the manuscript and the critical review of the draft manuscripts. D.N., T.A.T. and D.S. assisted with the design, analysis, and interpretations of the data and the manuscript drafts' critical evaluation. All authors have read and agreed to the published version of the manuscript.

\subsection{Funding}

The authors received no financial support for the research, authorship, and/or publication of this article.

\subsection{Acknowledgements}

Our deepest gratitude goes to all respondents in this study.

\subsection{Ethical Approval}

This study was conducted according to the guidelines laid down in the Declaration of Helsinki. All participants provided informed consent before completing the online survey.

\subsection{Data Availability Statement}

The data presented in this study are available on request from the corresponding author.

\subsection{Conflict of Interest}

The authors declare that they have no known competing financial interests or personal relationships that could have appeared to influence the work reported in this paper.

\section{References}

[1] Hui, D. S. (2017). Epidemic and Emerging Coronaviruses (Severe Acute Respiratory Syndrome and Middle East Respiratory Syndrome). Clinics in Chest Medicine, 38(1), 71-86. doi:10.1016/j.ccm.2016.11.007.

[2] Shoman, H., Karafillakis, E., \& Rawaf, S. (2017). The link between the West African Ebola outbreak and health systems in Guinea, Liberia and Sierra Leone: A systematic review. Globalization and Health, 13(1), 1. doi:10.1186/s12992-016-0224-2.

[3] Annan, A. A., Yar, D. D., Owusu, M., Biney, E. A., Forson, P. K., Okyere, P. B., Gyimah, A. A., \& Owusu-Dabo, E. (2017). Health care workers indicate ill preparedness for Ebola Virus Disease outbreak in Ashanti Region of Ghana. BMC Public Health, 17(1), 546. doi:10.1186/s12889-017-4474-6.

[4] Song, F., Shi, N., Chan, F., Zhang, Z., Shen, J., Lu, H., Ling, Y., Jiang, Y., \& Shi, Y. (2020). Emerging 2019 Novel Coronavirus (2019-nCoV) Pneumonia. Radiology, 295(1), 210-217. doi:10.1148/radiol.2020200274. 
[5] Xie, M., \& Chen, Q. (2020). Insight into 2019 novel coronavirus-An updated intrim review and lessons from SARS-CoV and MERS-CoV. International Journal of Infectious Diseases. doi:10.1016/j.ijid.2020.03.071.

[6] Afulani, P. A., Gyamerah, A. O., Aborigo, R., Nutor, J. J., Malechi, H., Laar, A., Sterling, M., \& Awoonor-Williams, J. K. (2020). Perceived preparedness to respond to the COVID-19 pandemic: A study with healthcare workers in Ghana. Journal of Global Health Science, 2(2), 24. doi:10.35500/jghs.2020.2.e24.

[7] Abebe, A., Mekuria, A., \& Balchut, A. (2020, August 24). <p>Awareness of Health Professionals on COVID-19 and Factors Affecting It Before and During Index Case in North Shoa Zone, Ethiopia, 2020</p>. Infection and Drug Resistance; Dove Press. doi:10.2147/IDR.S268033.

[8] Roupa, Z., Polychronis, G., Latzourakis, E., Nikitara, M., Ghobrial, S., Chrysafi, A., \& Noula, M. (2020). Assessment of Knowledge and Perceptions of Health Workers Regarding COVID-19: A Cross-Sectional Study from Cyprus. Journal of Community Health. doi:10.1007/s10900-020-00949-y.

[9] Bandyopadhyay, S., Baticulon, R. E., Kadhum, M., Alser, M., Ojuka, D. K., Badereddin, Y., ... Iharchane, S. (2020). Infection and mortality of healthcare workers worldwide from COVID-19: a systematic review. BMJ Global Health, 5(12), e003097. doi:10.1136/bmjgh-2020-003097.

[10] Nguyen, L. H., Drew, D. A., Graham, M. S., Joshi, A. D., Guo, C.-G., Ma, W., Mehta, R. S., Warner, E. T., Sikavi, D. R., Lo, C.-H., Kwon, S., Song, M., Mucci, L. A., Stampfer, M. J., Willett, W. C., Eliassen, A. H., Hart, J. E., Chavarro, J. E., RichEdwards, J. W., ... Zhang, F. (2020). Risk of COVID-19 among frontline healthcare workers and the general community: A prospective cohort study. The Lancet Public Health, 5(9), e475-e483. doi:10.1016/S2468-2667(20)30164-X.

[11] Elhadi, M., Msherghi, A., Alkeelani, M., Zorgani, A., Zaid, A., Alsuyihili, A., Buzreg, A., Ahmed, H., Elhadi, A., Khaled, A., Boughididah, T., Khel, S., Abdelkabir, M., Gaffaz, R., Bahroun, S., Alhashimi, A., Biala, M., Abulmida, S., Elharb, A., ... Amshai, A. (2020). Assessment of Healthcare Workers' Levels of Preparedness and Awareness Regarding COVID-19 Infection in Low-Resource Settings. The American Journal of Tropical Medicine and Hygiene, 103(2), 828-833. doi:10.4269/ajtmh.20-0330.

[12] Rodriguez-Morales, A. J., Cardona-Ospina, J. A., Gutiérrez-Ocampo, E., Villamizar-Peña, R., Holguin-Rivera, Y., EscaleraAntezana, J. P., Alvarado-Arnez, L. E., Bonilla-Aldana, D. K., Franco-Paredes, C., Henao-Martinez, A. F., Paniz-Mondolfi, A., Lagos-Grisales, G. J., Ramírez-Vallejo, E., Suárez, J. A., Zambrano, L. I., Villamil-Gómez, W. E., Balbin-Ramon, G. J., Rabaan, A. A., Harapan, H., ... Sah, R. (2020). Clinical, laboratory and imaging features of COVID-19: A systematic review and meta-analysis. Travel Medicine and Infectious Disease, 34, 101623. doi:10.1016/j.tmaid.2020.101623.

[13] Lechien, J. R., Chiesa-Estomba, C. M., Place, S., Van Laethem, Y., Cabaraux, P., Mat, Q., Huet, K., Plzak, J., Horoi, M., Hans, S., Rosaria Barillari, M., Cammaroto, G., Fakhry, N., Martiny, D., Ayad, T., Jouffe, L., Hopkins, C., Saussez, S., \& COVID-19 Task Force of YO-IFOS. (2020). Clinical and epidemiological characteristics of 1420 European patients with mildto-moderate coronavirus disease 2019. Journal of Internal Medicine, 288(3), 335-344. doi:10.1111/joim.13089. 